\title{
Fundamental Aspects of Resistance Sintering under Ultrahigh Pressure Consolidation
}

\author{
Zhangjian Zhou, Ji-Soon Kim ${ }^{a}$ and Young-Jin Yum ${ }^{b, *}$ \\ School of Materials Science and Engineering, University of Science and Technology Beijing, Beijing 100083, China \\ ${ }^{a}$ School of Materials Science and Engineering, University of Ulsan, Ulsan 680-749, Korea \\ ${ }^{b}$ School of Mechanical Engineering, University of Ulsan, Ulsan 680-749, Korea \\ (Received January 5, 2012; Revised January 25, 2012; Accepted February 1, 2012)
}

\begin{abstract}
The consolidation results of fine tungsten powders, W-Cu composite and W/Cu FGM by using a novel method combining resistance sintering with ultra high pressure have been reviewed. The densification effects of the consolidation parameters, including pressure, input power and sintering time, have been investigated. The sintering mechanism of this method was quite different from other sintering methods. Particle rearrangement, sliding, distortion and crushing due to the ultra high pressure are the dominant mehanisms at the initial stage, then the dominant sintering mechanisms are transient arc-fused processes controlled by the input power.
\end{abstract}

Keywords: Resistance sintering, Ultra high pressure, Functionally graded materials

\section{Introduction}

Novel materials that combine unusual properties such as super-plasticity in normally brittle materials, low coefficient thermal expansion and high melting point with high thermal conductivity have received considerable attention in recent years for use in critical technological applications. Most of these materials are in powder form and attribute their unique properties to a metastable condition, e.g., nanocrystalline, or a composition by two different materials, e.g., functionally graded materials (FGM) composed by materials with high melting point difference. Sintering is a key materials science subject that most materials products for use in key industries such as electronics, nuclear and aerospace are fabricated by sintering. Lots of novel sintering technologies, such as spark plasma sintering, mechanical alloying combined with hot isostatic pressing, and microwave sintering, have been developed during the past twenty years. However, it is still crucial to have processing methods to fabricate dense components by techniques that can retain the particle size or designed composition distribution in the final micro- structure.

Resistance sintering was applied to sintering conducted materials about half century ago. This method received renewed interests recently as a high-speed sintering which involves passing high electrical current through powder compact [1]. Most of the energy serves to melt that portion of the compact where migration is desirable for densification, while little energy is absorbed by the bulk materials. Naturally, this technique is suitable for conductive powders. This method also enables for unsinterable materials. But it is not sufficient to apply normal resistance sintering techniques to get high density refractory material products.

Pressure application is known to assist the densification process by enhancing sintering processes and thus reducing the high temperature exposure of the consolidation powder. Many studies have demonstrated the effect of the additionally applied ultra-high pressures (higher than $1 \mathrm{GPa}$ ) during consolidation on the densification of ultrafine grained (UFG) materials with high density [2-4].

If we combine the advantages of resistance sintering and those of ultra-high pressure consolidation, this novel

*Corresponding Author : Y. J. Yum, TEL: +82-52-259-2132, FAX: +82-259-1680, E-mail: yjyum@ulsan.ac.kr 
Table 1 Relative density, hardness and bending strength of sintered pure W

\begin{tabular}{lcccccc}
\hline \hline \multicolumn{1}{c}{ Samples } & W10-1 & W10-2 & nW & W02 & W10 & W100 \\
\hline Powder size, $\mu \mathrm{m}$ & 1 & 1 & 0.05 & 0.2 & 1 & 10 \\
\hline \multirow{2}{*}{ Sintering conditions } & $9 \mathrm{GPa}, 0 \mathrm{~kW}$, & $9 \mathrm{GPa}, 18 \mathrm{~kW}$, & $9 \mathrm{GPa}, 23 \mathrm{~kW}$, & $9 \mathrm{GPa}, 23 \mathrm{~kW}$, & $9 \mathrm{GPa}, 23 \mathrm{~kW}$, & $9 \mathrm{GPa}, 23 \mathrm{~kW}$, \\
Relative density\% & $30 \mathrm{~s}$ & $30 \mathrm{~s}$ & $60 \mathrm{~s}$ & $60 \mathrm{~s}$ & $60 \mathrm{~s}$ & $60 \mathrm{~s}$ \\
Micro HardnessHV & 94.85 & 96.63 & 91.57 & 95.25 & 97.93 & 98.97 \\
Bending strength, MPa & 458.3 & 665.9 & 1090.7 & 969.5 & 776.5 & 475.6 \\
\hline
\end{tabular}
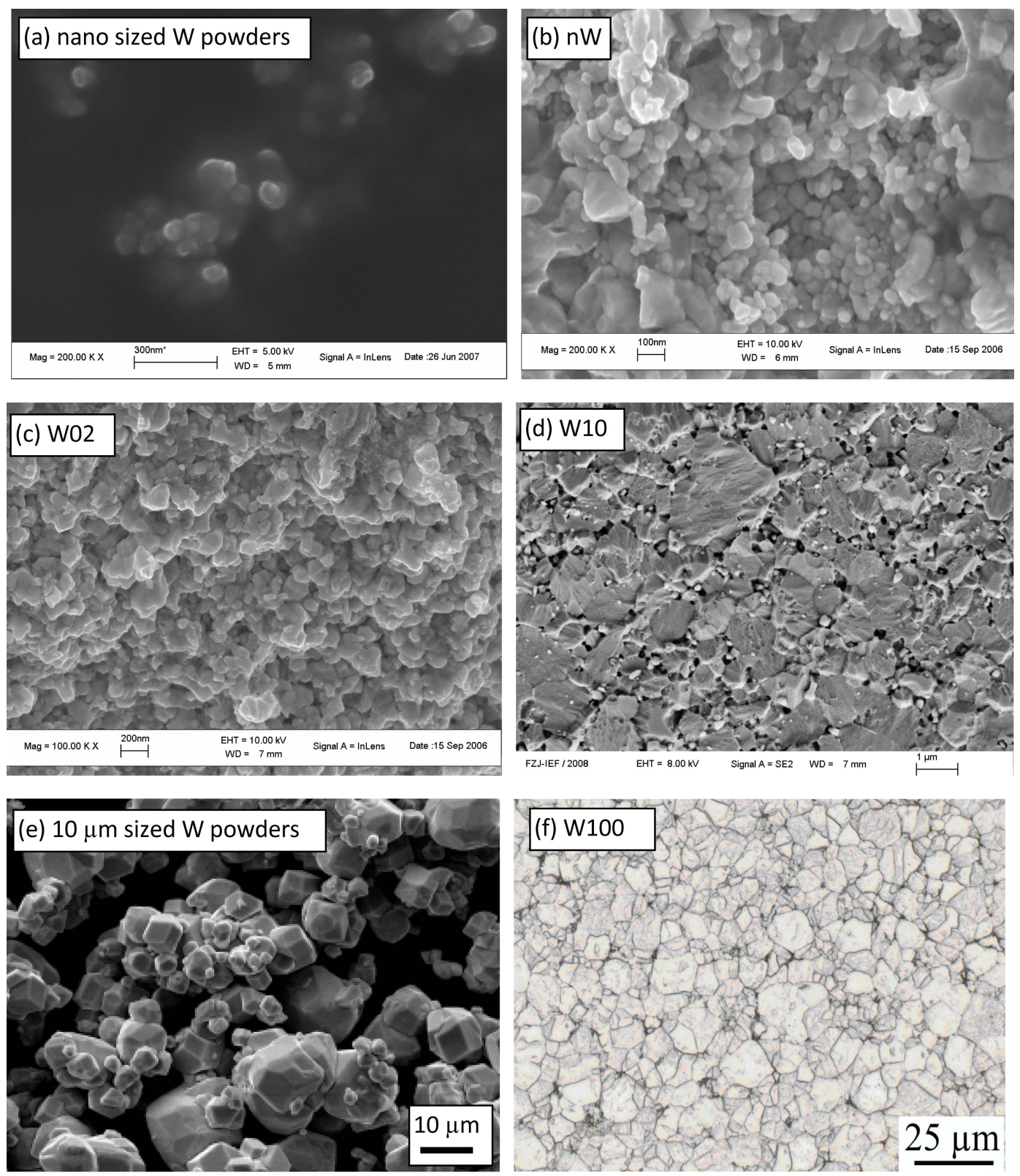

Fig. 1. Morphology of $W$ powders and the sintered samples, (a) $W$ powders with average particle size of 50 nm; (b) fracture surface morphology of sample nW; (c) fracture surface morphology of sample W02; (d) fracture surface morphology of sample W10; (e) W powders with average particle size of $10 \mu \mathrm{m}$, and (f) cross section surface morphology of sample W100.

sintering technology will show specific advantages: the ultra high pressure can provide the green compact with a high density; the compact will be heated mainly by Joule heat, which can change the sintering temperature quickly; a low sintering temperature and a very short sintering time may be sufficient. All these advantages are favor- 
able for preventing the grain growth and composition migration.

In this paper we reviewed results obtained with a process that consolidates UFG refractory metal, FGM composed by materials with high melting point difference by this novel technology, resistance sintering under ultra high pressure (RSUHP) [5-7].

\section{Fabrication of UFG Refractory Metals}

Commercially received $\mathrm{W}$ powders with average particle sizes of $50 \mathrm{~nm}$ and 0.2 to $10 \mu \mathrm{m}$ were consolidated by RSUHP. The details of the process and setup can be found in reference [5]. Table 1 shows the relative density, micro-hardness and bending strength of pure $\mathrm{W}$ with different grain sizes and different sintering parameters. The relative densities of sintered compacts composed of micron sized $\mathrm{W}$ powders were rather high, nearly $98 \%$ for $1 \mu \mathrm{m}$ sized powder and $99 \%$ for $10 \mu \mathrm{m}$ sized powder, but the sinter density of sub-micron sized powders still needs further increase in future works.

Fig. 1 shows the micrographs of $\mathrm{W}$ powders with different particle sizes and $\mathrm{W}$ samples consolidated under pressures of $9 \mathrm{GPa}$, an electric input power of $23 \mathrm{~kW}$ and sintering times of $60 \mathrm{~s}$. It can be seen that for all sintered pure $\mathrm{W}$ specimens, the mean grain sizes were still nearly the same to or even less than the initial powder sizes. These results demonstrate that RSUHP is a promising technology to fabricate UFG refractory metal.

Due to the fine grain size, all samples showed a high micro-hardness, as shown in Table 1. It is obvious that the finer the grain size, the higher the micro-hardness and the bending strength will be, except for the sample of $\mathrm{nW}$, which shows very high micro-hardness, but rather poor bending strength due to the low density (high porosity). It is also found that the micro-hardness and bending strength of the sample consolidated from $1 \mu \mathrm{m}$ powders by ultra high pressure only (without additional ohmic heating) were far less than those of the sintered one, although the densities of these two samples are close. Obviously, the applied current has a stronger effect on the increase of the bending strength than on the density of the material.

\section{Fabrication of $\mathrm{W} / \mathrm{Cu}$ Composite and W/Cu FGM}

$\mathrm{W}$ powder with an average particle size of $1 \mu \mathrm{m}$ and a
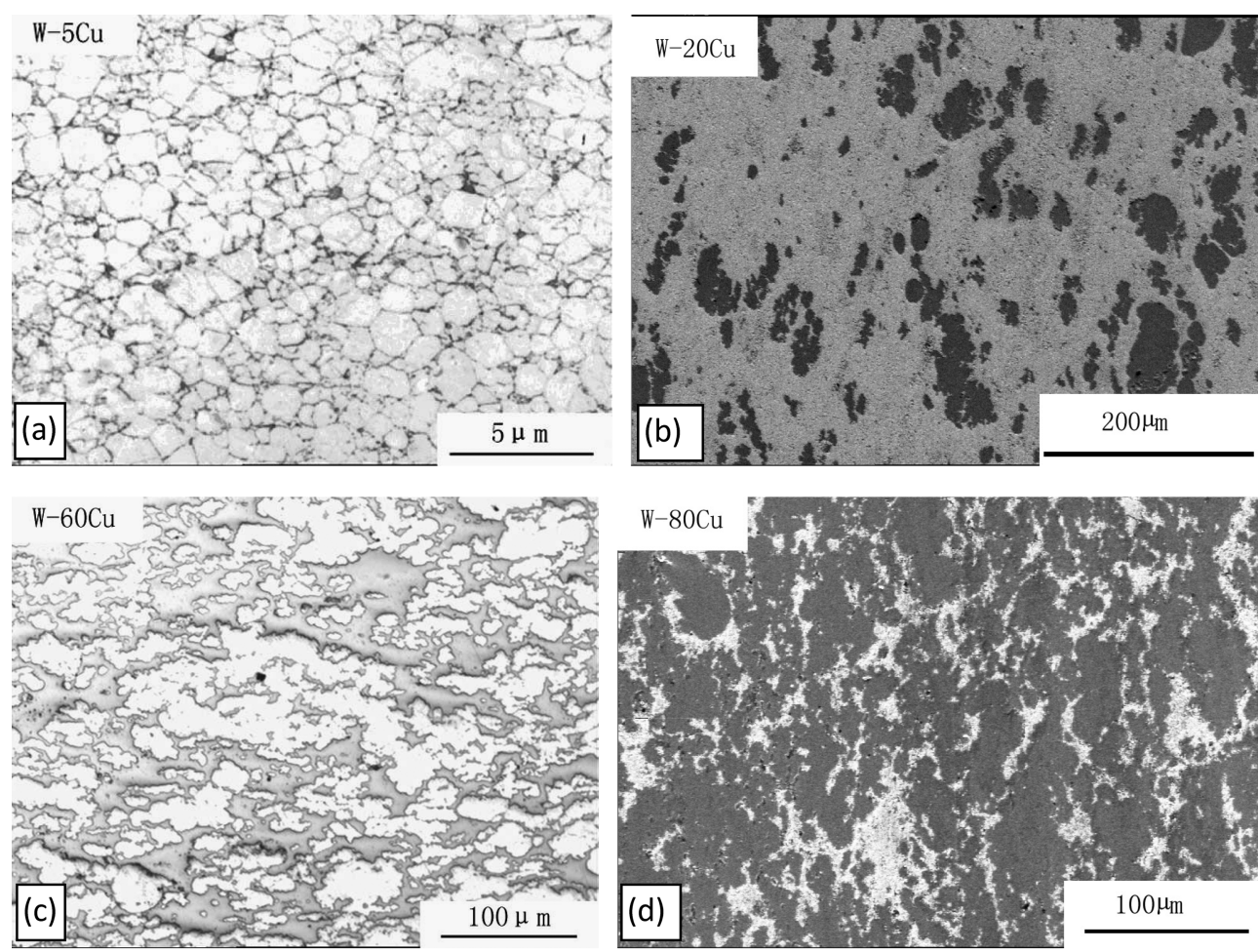

Fig. 2. The morphology of $\mathrm{W}-\mathrm{Cu}$ composites. 


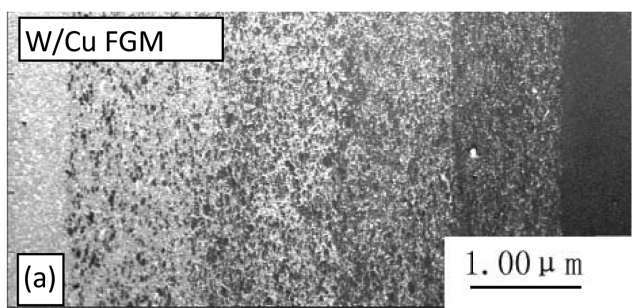

Fig. 3. Cross-section morphology of well-sintered W/Cu FGM, (a) 6-layered W/Cu FGM, and (b) 11-layered W/Cu/W FGM.

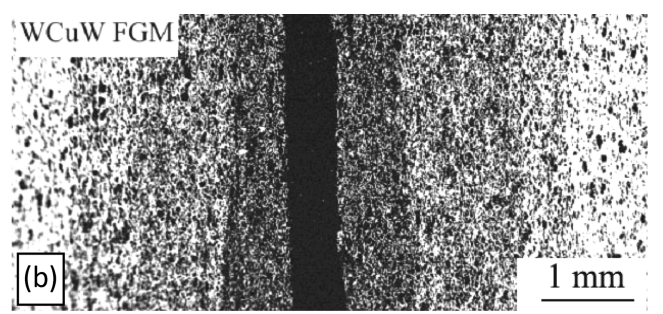

purity of $>99.5 \%$ and $\mathrm{Cu}$ powder with a particle size of $<74 \mu \mathrm{m}$ and a purity of $>99.9 \%$ are mixed in an agate mortar with different volume ratios according to the composition design. Fig. 2 shows the SEM morphology of W-Cu composites fabricated under pressure of $8 \mathrm{GPa}$, input power of $23 \mathrm{~kW}$ and holding time of 50 seconds. A good sintered W-5Cu composite was obtained, W particles being well bonded together. The average particle size remained about $1 \mu \mathrm{m}$ and no obvious grain growth was observed. In the $\mathrm{W}-20 \mathrm{Cu}$ composite, isolated $\mathrm{Cu}$ particles were dotted in $\mathrm{W}$ matrix just the same as in the W$80 \mathrm{Cu}$ composite, where $\mathrm{W}$ particles were dispersed in the $\mathrm{Cu}$ matrix. In the $\mathrm{W}-60 \mathrm{Cu}$ composite, a homogeneous net distribution could be found between $\mathrm{W}$ and $\mathrm{Cu}$ phase.

Fig. 3 is the backscattering image of the cross section of $\mathrm{W} / \mathrm{Cu}$ FGM with different composition design, in which the $\mathrm{W}$ component is white and the $\mathrm{Cu}$ is black. A good graded composition transition is found from the morphology of overall 6-layered W/Cu FGM (see Fig. $3(\mathrm{a})$, the composition design in volume ratio is pure $\mathrm{W}$, $\mathrm{W}+20 \% \mathrm{Cu}, \mathrm{W}+40 \% \mathrm{Cu}, \mathrm{W}+60 \% \mathrm{Cu}, \mathrm{W}+80 \% \mathrm{Cu}$, and pure $\mathrm{Cu}$ ). The interfaces between layers are distinct and no defects or impurities. This reveals that there has been no obvious composition migration during the short sintering time. The relative density of the FGM was $97.2 \%$. Fig. 3(b) shows the morphology of a 11-layered $\mathrm{W} / \mathrm{Cu} / \mathrm{W}$ FGM with the composition design (in volume ratio) of $\mathrm{W}$ only, $\mathrm{W} 20 \% \mathrm{Cu}, \mathrm{W} 40 \% \mathrm{Cu}, \mathrm{W} 60 \% \mathrm{Cu}, \mathrm{W} 80 \% \mathrm{Cu}, \mathrm{Cu}$ only, $\mathrm{W} 80 \% \mathrm{Cu}, \mathrm{W} 60 \% \mathrm{Cu}, \mathrm{W} 40 \% \mathrm{Cu}, \mathrm{W} 20 \% \mathrm{Cu}, \mathrm{W}$ only for each layer respectively. This result further confirms that the designed composition distribution of W/Cu FGM can be preserved rather well by resistance sintering under ultra high pressure.

\section{The Densification Analysis}

There have three important consolidation parameters during the RSUHP process: pressure, the electric input power and the time it was applied (sintering time). These parameters will show different densification effects during consolidation of $\mathrm{W}$ powders with different particle size and $\mathrm{W} / \mathrm{Cu}$ composite.

When only pressure was loaded on the samples without additional electric heating, densification occurs simply by the motion of particle centers toward each other in several stages. The first stage of the compaction process is sliding and restacking of powder particles at low pressures, which leads to rearrangement of the powder from a loose array to close packing. At a certain relative density, the particles are more or less in a fixed arrangement. Due to the resistance of a material against deformation, the internal stress of the particles increases. The following stage can be divided into two main deformation mechanisms: In ductile systems, after reaching yield strength, $\sigma_{y}$, the particles yield and start to deform plastically which results in a permanent change of the particle shape. In contrast, for brittle systems, particles fragment into smaller units at fracture strength, $\sigma_{f}$. Material fracture will eventually occur at higher deformations. As shown in Fig. 4(a), the fracture surface morphology of W produces from a $1 \mu \mathrm{m}$ powder which was consolidated only by ultra high pressure of $9 \mathrm{GPa}$. It can be seen that the powders were compacted and form a rather dense solid body. Some particles were still equal to the initial powder size of $1 \mu \mathrm{m}$ size, but most of the particles were less than $1 \mu \mathrm{m}$ in size. This is an indication that ultra high pressures can crush and deform particles from the utilized powders, and thus make an important effect on densification mainly by particle rearrangement, sliding, distortion and crushing mechanisms. This result also hints that RSUHP is a potential way to fabricate materials with nano structure through the way of "top-to-down".

When strong current passed through the compact, the sintering mechanism is then would be mainly controlled 

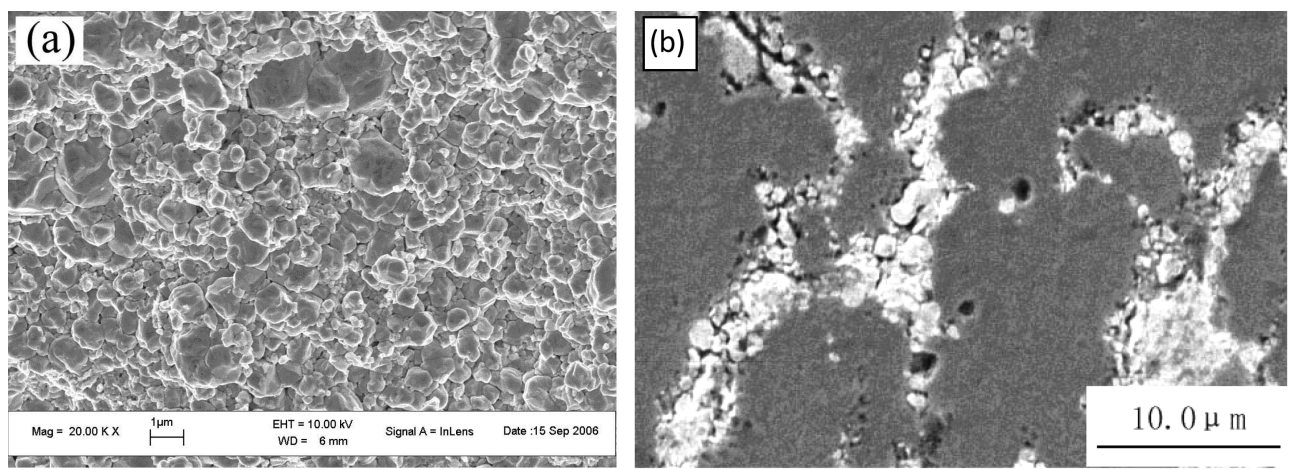

Fig. 4. The morphology of pure W (a) and W-Cu composites (b) consolidated by ultra-high pressure of 9 GPa, without resistance sintering.

by the input power, i.e. by the ohmic heat which is generated inside the compact. However, the input power has only little influence on the density, as shown in Table 1, but obvious strong effects on hardness and bending strength of pure W. The explanation was that the particles should be mainly mechanically combined when only ultra high pressure was loaded. But when very strong current passed through the compact, Joule heat would be produced quickly and sintered the compact due to the resistance of $\mathrm{W}$ green compact. For technical reasons, we can't measure the exact temperature of the sample during sintering due to the limitation of the pressure vessel. But according to the experience, i.e. whether melting occurred on the steel platelet and the color change of the inner surface of pyrophyllite sleeve, the whole temperature of the sample should be less than $1200^{\circ} \mathrm{C}$, which is far below the normal sintering temperature of $\mathrm{W}$. But the temperature at the interface of $\mathrm{W}$ particles should be very high due to the high contact resistance on the particle interface, thus surface diffusion or even surface melting may occur quickly and bonding particles together when strong current passed through. We call this sintering mechanism as transient arc-fused mechanism, which is similar to fusion welding process. The bonding level of different grains should be mainly controlled by contact resistance between particles, i.e. controlled by the width and shape of the gaps between particles. The structure homogeneity of the green compact is one of the key factors for controlling the sintering quality of sample by RSUHP.

For composite and FGM, when ultra high pressure was loaded, it can be supposed that particle rearrangement, plastic deformation and sliding will occur quickly, especially in the $\mathrm{Cu}$ particle due to its excellent plasticity.
Thus a very high density will be obtained. This can be proved in Fig. 4(b), in which show the morphology of the $\mathrm{W}-20 \mathrm{Cu}$ composite, where only 8Gpa was applied and no current passed through. It can be seen that the $\mathrm{Cu}$ had been well bonded together, but there are still a lot of close pores in the tungsten particles because of lacks of plastic deformation and sliding under ultra-high pressure due to its brittle and high hardness.

When high current passed through the green compact, different resistance will be applied by difference resistivity between $\mathrm{W}$ and $\mathrm{Cu}$. It can be expected that a gradual resistance distribution and thus an elevated temperature zone will be constructed when strong current passes through the W/Cu FGM green compact. The temperature of tungsten particle would increase quickly due to its high resistance, and simultaneously, tungsten particles would be bonded together by sintering. At the same time, the $\mathrm{Cu}$ particles would produce very little Joule heat due to their low resistance, but a significant amount of heat would be conducted from the $\mathrm{W}$ particles to $\mathrm{Cu}$ particles owing to the high thermal conductivity of copper. Therefore, the sintering time should be very short to avoid the copper getting too hot, and even melting, which is harmful for preserving the composition distribution.

\section{Conclusions}

The main advantages of the RSUHP process in comparison to other conventional sintering processes are the very short sintering time and very fast heating and cooling rates. The consolidation of fine $\mathrm{W}$ powders show encouraging results on fabrication of ultra fine grained metal. The grain sizes of all samples are nearly still same 
to or even smaller than the initial powder size. The consolidation of composite and FGM composed with high melting point different materials show that by this method, micro component migration can be avoid, thus the composition distribution can be well retained.

The sintering mechanism of RSUHP is quite different compared to conventional sintering methods. The pressure and input power show significant effects on densification. At the initial stage the dominant mechanisms are particle rearrangement, sliding, distortion and crushing due to the ultra high pressure, while during the later stage, transient arc-fused processes controlled by the input power are the dominant sintering mechanisms.

Resistance sintering under ultra high pressure is fundamentally different from the conventional sintering, which involves ultra high pressure/resistance heating followed by transfer of thermal energy only via particle surface. Microwave heating is a volumetric heating involving conversion of electromagnetic energy into thermal energy, which is. The use of RSUHP for materials processing has major potential, and real advantages over conventional heating due to its significant advantages, including considerably reduced processing time and temperature, Time and energy savings, Fine microstructures and hence improved mechanical properties and better product performance, rapid and highly efficient. Lower temperatures and shorter holding times have made it possible to sinter nanometric powders to near theoretical values with little grain growth.

So far, there has been little effort devoted to understanding the mechanisms and the science behind RSUHP of metals. There are many factors that contribute signifi- cantly to the total resistance heating of powdered metals under ultra high pressure. The sample size and shape, the distribution of the cavities between particles are all important in the heating and sintering of powder metals. This research is just at the early stages, and it will be a long time before the exact mechanisms are elucidated.

\section{Acknowledgements}

The authors would like to express their thanks for the financial support of National Natural Science Foundation of China under grant No. 50634060.

\section{References}

[1] S. Maki, Y. Harada and K. Mori: Mater. Sci. Forum, 449452 (2004) 281-284.

[2] K. Moon, H. Park and K. Lee: Mater. Sci. Eng. A, 323 (2002) 293-300.

[3] F. Maglia, U. Anselmi-Tamburini, G Chiodelli, H. Ecamurlu, M. Dapiaggi and Z. A. Munir: Solid State Ionics, 180 (2009) 36-40.

[4] R. M. German and E. Olevsky: International J. of Refractory Metals \& Hard Mater., 23 (2005) 294-300.

[5] Z. Zhou, J. Du, S. Song and C. Ge: J. of Alloy and Compound, 428 (2007) 146-150.

[6] Zhangjian Zhou, Juan Du, Shuxiang Song, et al.: Journal of Nanoscience and Nanotechnology, 9(2) (2009) 809-812.

[7] Zhangjian Zhou and Young-Soon Kwon: J. of Mater. Processing Technology, 168 (2005) 107-111.

이 논문을 지난 30 여 년간 한국분말야금학회 발전 및 기술개발에 큰 업적을 남기신 울산대학교 권영순 교수님의 정년을 기념하여 헌정합니다. 